\title{
Facile one-pot synthesis of functionalized organophosphonate esters via ketone insertion into bulky arylphosphites
}

\author{
RAMASWAMY MURUGAVEL* and SUBRAMANIAM KUPPUSWAMY \\ Department of Chemistry, Indian Institute of Technology Bombay, Powai, Mumbai 400076 \\ e-mail: rmv@chem.iitb.ac.in
}

\begin{abstract}
The reaction of phosphorus trichloride with 2,6-diisopropyl phenol in the presence of $\mathrm{LiCl}$ under reflux conditions for $24 \mathrm{~h}$ produces a mixture of $(\mathrm{ArO}) \mathrm{PCl}_{2}$ and $(\mathrm{ArO})_{2} \mathrm{PCl}\left(\mathrm{Ar}=2,6-i \mathrm{Pr}_{2} \mathrm{C}_{6} \mathrm{H}_{3}\right)$. The hydrolysis of the aryloxy compounds in acetone $/ \mathrm{H}_{2} \mathrm{O}$ results in the formation of two novel phosphonate ester derivatives $\left[(\mathrm{ArO}) \mathrm{P}(\mathrm{O})(\mathrm{OH})\left(\mathrm{CMe}_{2} \mathrm{OH}\right)\right](\mathbf{1})$ and $\left[(\mathrm{ArO})_{2} \mathrm{P}(\mathrm{O})\left(\mathrm{CMe}_{2} \mathrm{OH}\right)\right](2)$, respectively in a moderate yield. The title compounds have presumably formed via acetone insertion to the $\mathrm{P}-\mathrm{H}$ bonds of $(\mathrm{ArO}) \mathrm{P}(\mathrm{O})(\mathrm{H})(\mathrm{OH})$ and $(\mathrm{ArO})_{2} \mathrm{P}(\mathrm{O})(\mathrm{H})$, respectively, in the presence of $\mathrm{HCl}$ produced during the hydrolysis. Compounds 1 and $\mathbf{2}$ have been characterized by elemental analysis, and ESI-mass, Infrared and NMR spectroscopic techniques. Further, solid state structures of $\mathbf{1}$ and $\mathbf{2}$ have been established by single crystals X-ray diffraction studies.
\end{abstract}

Keywords. One-pot synthesis; acetone insertion; new phosphonate esters; X-ray structure.

\section{Introduction}

Phosphonates have been recognized for a long time as important intermediates in synthetic organic chemistry. ${ }^{1,2}$ On the other hand, phosphonic acids ${ }^{3,4}$ and phosphate esters ${ }^{5-10}$ are important classes of compounds in inorganic chemistry, being widely used for synthesizing large molecular clusters and zeolite building blocks. Although several synthetic methods are available to prepare phosphonate esters through Arbuzov reaction, very few examples have been reported for their synthesis via phosphite insertion into electropositive centers under highly acidic conditions. ${ }^{11}$ Modified Mannich type procedure has been applied to synthesize newer phosphonates, starting from phosphorus acid, amine and formaldehyde according to (1). This reaction however proceeds efficiently only under highly acidic conditions. A further limitation of this reaction is that only formaldehyde can be used as the carbonyl source at low $\mathrm{pH}{ }^{12}$ This methodology was later extended to the synthesis of aminoethylene phosphonic acid and N-benzyl- $\alpha$ aminophosphonic acids. ${ }^{13-15}$

$$
\begin{array}{r}
\mathrm{R}_{2} \mathrm{NH}+\mathrm{HCHO}+\mathrm{HP}(\mathrm{O})(\mathrm{OH})_{2} \stackrel{\mathrm{HCl}}{\longrightarrow} \\
\mathrm{R}_{2} \mathrm{NCH}_{2} \mathrm{P}(\mathrm{O})(\mathrm{OH})_{2}+\mathrm{H}_{2} \mathrm{O} .
\end{array}
$$

\footnotetext{
*For correspondence
}

Acidic nature of the $\mathrm{P}-\mathrm{H}$ protons is not only useful for the phosphonate ester preparation, but has also found several applications such as reducing reagent, ${ }^{15}$ synthesis of biologically relevant compounds, ${ }^{16}$ and selective diastereomer formation. ${ }^{17} \mathrm{~A}$ further problem that arises due to the application of a strongly acidic medium is the ester hydrolysis, leading to the loss or decomposition of desired products. Hence the preparation of phosphonates esters is best carried out under mild conditions. We have overcome this problem by starting from aryloxy $\mathrm{P}$ (III) chlorides and performing the synthesis of phosphonic acid as well as the subsequent carbonyl compound insertion in one-pot, exploiting the $\mathrm{HCl}$ by-product formed in the $\mathrm{P}-\mathrm{Cl}$ hydrolysis step. In this communication, we report the details of this investigation.

\section{Experimental}

\subsection{Apparatus}

All reactions were carried out under anaerobic conditions unless specified otherwise. The ${ }^{1} \mathrm{H}\left(\mathrm{Me}_{4} \mathrm{Si}\right.$ internal standard $)$ and ${ }^{31} \mathrm{P}\left(85 \% \mathrm{H}_{3} \mathrm{PO}_{4}\right.$ external standard) NMR spectra were recorded on a Varian AS 300 spectrometer. Infrared spectra were obtained on a Perkin Elmer Spectrum One FT-IR spectrometer. Microanalyses were performed on a Thermo Finnigan (FLASH EA 1112) or a Carlo Eraba 1106 microanalyzer. ESI-Mass spectra were obtained on a 
Waters Q-TOF micro-YA-105 spectrometry. Commercial grade solvents were purified by employing conventional procedures and were distilled prior to their use. Commercially available starting materials such as $\mathrm{PCl}_{3}$ (s.d. Fine-Chem.), $\mathrm{LiCl}$ (Lancaster) and 2,6-diisopropyl phenol (Lancaster) were used as procured.

\subsection{Synthesis of $(\mathrm{ArO}) \mathrm{PCl}_{2}$ and $(\mathrm{ArO})_{2} \mathrm{PCl}$}

Phosphorus trichloride (10 mL, $115 \mathrm{mmol}), 2$,6diisopropyl phenol $(5 \mathrm{~mL}, 43 \mathrm{mmol})$ and $\mathrm{LiCl}$ $(125 \mathrm{mg})$ were heated under reflux for $24 \mathrm{~h}$. The reaction mixture was allowed to cool to room temperature and filtered. The unreacted phosphorus trichloride was removed under reduced pressure. The resultant liquid was distilled under vacuum at $125^{\circ} \mathrm{C} / 0.5$ torr. The distillate is $(\mathrm{ArO}) \mathrm{PCl}_{2}$ while the liquid that did not distil under this pressure is predominately the disubstituted product $(\mathrm{ArO})_{2} \mathrm{PCl}$.

\subsection{Synthesis of $\left[(\mathrm{ArO}) \mathrm{P}(\mathrm{O})(\mathrm{OH})\left(\mathrm{CMe}_{2} \mathrm{OH}\right)\right](\mathrm{1})$}

(ArO) $\mathrm{PCl}_{2}$ was treated with aqueous acetone at room temperature. Resultant mixture was filtered out and filtrate was kept at room temperature for the crystallization. Colourless needle shape single crystals of 1 were isolated after 2 days. m.p: $182-183^{\circ} \mathrm{C}$. Yield: $1.4 \mathrm{~g}(12 \%)$. Anal. Calcd. for $\mathrm{C}_{15} \mathrm{H}_{25} \mathrm{PO}_{4}(\mathrm{Mr}=$ 300.33): C, 59.99; H, 8.39. Found; C, 59.02; H, 8.23. IR (KBr, cm $\left.{ }^{-1}\right): 3423(b r), 3116(w), 2975(s)$, $2930(w), 2870(w), 2329(b r), 1634(b r), 1467(m)$, $1445(m), 1383(w), 1333(w), 1240(s), 1159(v s)$, $1097(\mathrm{~m}), 1046(w), 970(v s), 937(v s), 852(\mathrm{~m}), 800$ $(m), 752(m) .{ }^{1} \mathrm{H}$ NMR (pyridine- $\left.d_{5}, 300 \mathrm{MHz}\right) \delta$ : 7.13-7.22 (m, 3H, Ar-H), 4.40-4.49 (septet, 2H, $\left.\mathrm{CH}\left(\mathrm{CH}_{3}\right)_{2} ;{ }^{3} J_{\mathrm{HH}}=6.9 \mathrm{~Hz}\right), 2.00\left(s, 3 \mathrm{H}, \mathrm{CH}_{3}\right), 1.95$ $\left(s, 3 \mathrm{H}, \mathrm{CH}_{3}\right), 1.29-1.31\left(d, 12 \mathrm{H}, \mathrm{CH}\left(\mathrm{CH}_{3}\right)_{2},{ }^{3} \mathbf{J}_{\mathrm{HH}}=\right.$ $6.9 \mathrm{~Hz}$ ). ${ }^{31} \mathrm{P}$ NMR (pyridine- $\left.d_{5}, 121 \mathrm{MHz}\right) \delta$ : $22.6 \mathrm{ppm}$. ESI Mass spectrum (acetone): $\mathrm{m} / \mathrm{z} 1201$ $(4 \mathrm{M}+1)^{+}, \quad 901 \quad(3 \mathrm{M}+1)^{+}, \quad 601 \quad(2 \mathrm{M}+1)^{+}, \quad 301$ $(\mathrm{M}+1)^{+}$.

\subsection{Synthesis of $\left[(\mathrm{ArO})_{2} \mathrm{P}(\mathrm{O})\left(\mathrm{CMe}_{2} \mathrm{OH}\right)\right]$ (2)}

The distillation residue containing $(\mathrm{ArO})_{2} \mathrm{PCl}$ was dissolved in $\mathrm{H}_{2} \mathrm{O}$ /acetone and allowed to crystallize in aerobic atmosphere at room temperature. After 3 days well formed colorless rectangular crystals of 2 were obtained from the reaction mixture. M.p: $172-174^{\circ} \mathrm{C}$. Yield: $2.4 \mathrm{~g}$ (25\%). Anal. Calcd. for
$\mathrm{C}_{27} \mathrm{H}_{41} \mathrm{PO}_{4}(\mathrm{Mr}=460.59): \mathrm{C}, 70 \cdot 41 ; \mathrm{H}, 8.97$. Found; C, 69.5; H, 9.55. IR $\left(\mathrm{KBr}, \mathrm{cm}^{-1}\right): 3310(s), 3062(w)$, $2954(\mathrm{~s}), 2867(\mathrm{~m}), 1466(\mathrm{~m}), 1439(\mathrm{~m}), 1378(w)$, $1333(w), 1248(s), 1188(m), 1165(s), 1092(m)$, $1108(w), 1045(w), 975(w), 931(v s), 883(w), 798$ $(w), 772(m), 763(m) .{ }^{1} \mathrm{H}$ NMR (pyridine- $d_{5}$, $300 \mathrm{MHz}) \delta: 7.20(s, 6 \mathrm{H}, \mathrm{Ar}-\mathrm{H}), 5.53(b r, 1 \mathrm{H}, \mathrm{OH})$, 3.86-3.95 (septet, $4 \mathrm{H}, \mathrm{CH}\left(\mathrm{CH}_{3}\right)_{2} ;{ }^{3} J_{\mathrm{HH}}=6.6 \mathrm{~Hz}$ ), $2.01\left(s, 3 \mathrm{H}, \mathrm{CH}_{3}\right), 1.95\left(s, 3 \mathrm{H}, \mathrm{CH}_{3}\right), 1.25-1.28(d$, $\left.12 \mathrm{H}, \mathrm{CH}\left(\mathrm{CH}_{3}\right)_{2},{ }^{3} \mathrm{~J}_{\mathrm{HH}}=6.6 \mathrm{~Hz}\right), 1 \cdot 12-1.14(d, 12 \mathrm{H}$, $\mathrm{CH}\left(\mathrm{CH}_{3}\right)_{2},{ }^{3} \mathrm{~J}_{\mathrm{HH}}=6.6 \mathrm{~Hz}$ ). ${ }^{31} \mathrm{P}$ NMR (pyridine- $d_{5}$, $121 \mathrm{MHz}$ ) $\delta: 15.4 \mathrm{ppm}$. ESI Mass spectrum (pyridine): $m / z 461(\mathbf{M}+1)^{+}$.

\subsection{Single crystal X-ray diffraction studies}

Intensity data for $\mathbf{1}$ and $\mathbf{2}$ were collected on a Bruker AXS and Oxford XCalibur CCD diffractometers, respectively. All calculations were carried out using the programs in WinGX module. ${ }^{18}$ The structure solution was achieved by direct methods using SIR-92. ${ }^{19}$ The final refinement of the structure was carried out using full least-squares methods on $F^{2}$ using SHELXL$97 .{ }^{20}$ Selected crystal data are given table 1 . The details of crystal structure determination can either be

Table 1. Crystal data for 1 and 2.

\begin{tabular}{|c|c|c|}
\hline Compound & 1 & 2 \\
\hline Identification code & mur119 & $\mathrm{rm} 118 \mathrm{a}$ \\
\hline Empirical formula & $\mathrm{C}_{15} \mathrm{H}_{25} \mathrm{O}_{4} \mathrm{P}$ & $\mathrm{C}_{27} \mathrm{H}_{41} \mathrm{O}_{4} \mathrm{P}$ \\
\hline$F w$ & $300 \cdot 32$ & $460 \cdot 57$ \\
\hline Temperature (K) & $293(2)$ & $293(2)$ \\
\hline Wavelength $(\AA)$ & 0.71073 & 0.71073 \\
\hline Crystal system & Monoclinic & Triclinic \\
\hline Space group & $P 2_{1}$ & $P-1$ \\
\hline$a(\AA)$ & $10 \cdot 5157(17)$ & $9 \cdot 1694(13)$ \\
\hline$b(\AA)$ & $5.7611(9)$ & $11 \cdot 1482(10)$ \\
\hline$c(\AA)$ & $13 \cdot 306(2)$ & $14 \cdot 1469(9)$ \\
\hline$\alpha\left({ }^{\circ}\right)$ & 90 & $90 \cdot 253(6)$ \\
\hline$\beta\left({ }^{\circ}\right)$ & $95 \cdot 445(2)$ & $104 \cdot 059(7)$ \\
\hline$\gamma\left({ }^{\circ}\right)$ & 90 & $99 \cdot 521(9)$ \\
\hline$V\left(\AA^{3}\right)$ & $802 \cdot 5(2)$ & $1382 \cdot 0(2)$ \\
\hline$Z$ & 2 & 2 \\
\hline$D$ (calcd.) $\left(\mathrm{mg} / \mathrm{m}^{3}\right)$ & $1 \cdot 243$ & $1 \cdot 107$ \\
\hline Abs coeff. $\left(\mathrm{mm}^{-1}\right)$ & $0 \cdot 181$ & $0 \cdot 127$ \\
\hline$F(000)$ & 324 & 500 \\
\hline Cryst size $\left(\mathrm{mm}^{3}\right)$ & $0.15 \times 0.05 \times 0.05$ & $0.36 \times 0.32 \times 0.30$ \\
\hline$\theta$ range $\left(^{\circ}\right)$ & $1 \cdot 54$ to $24 \cdot 15$ & 1.49 to $25 \cdot 00$ \\
\hline Data/restraints/params & $1429 / 1 / 189$ & $4870 / 0 / 317$ \\
\hline Goodness-of-fit on $F^{2}$ & $1 \cdot 111$ & 1.007 \\
\hline$R_{1}[I>2 \sigma(I)]$ & 0.0254 & 0.0597 \\
\hline$R_{2}[I>2 \sigma(I)]$ & $0 \cdot 0632$ & $0 \cdot 1137$ \\
\hline
\end{tabular}


obtained from CCDC (deposition numbers 671174 and 671175 ) or directly from the authors.

\section{Results and discussion}

\subsection{Synthesis and characterization}

The reaction of 2,6-diisopropyl phenol with $\mathrm{PCl}_{3}$ in the presence of $\mathrm{LiCl}$ under reflux conditions for $24 \mathrm{~h}$ produces $(\mathrm{ArO}) \mathrm{PCl}_{2}$ and $(\mathrm{ArO})_{2} \mathrm{PCl}$. The reaction mixture was distilled under vacuum to obtain pure (ArO) $\mathrm{PCl}_{2}$. Hydrolysis of ( $\left.\mathrm{ArO}\right) \mathrm{PCl}_{2}$ in the presence of aqueous acetone leads to the formation of the bulky aryloxy group substituted phosphonate ester derivative $\left[(\mathrm{ArO}) \mathrm{P}(\mathrm{O})(\mathrm{OH})\left(\mathrm{CMe}_{2} \mathrm{OH}\right)\right]$ (1). Similarly, the hydrolysis of $(\mathrm{ArO})_{2} \mathrm{PCl}$ under similar conditions leads to the isolation of phosphonate diester $\left[(\mathrm{ArO})_{2} \mathrm{P}(\mathrm{O})\left(\mathrm{CMe}_{2} \mathrm{OH}\right)\right](2)$ in moderate yield.

The single crystals of $\mathbf{1}$ and $\mathbf{2}$, obtained directly from the reaction mixture, have been found to be analytically pure. The compounds have been further characterized by IR, ESI-mass and NMR spectroscopic techniques. Elemental analysis values in each case supported the chemical formulation for these compounds. Infrared spectrum of $\mathbf{1}$, shows a broad vibration at $2329 \mathrm{~cm}^{-1}$ corresponding to the presence of $\mathrm{PO}-\mathrm{H}$ group. The strong bands observed at around 1159 and $3423 \mathrm{~cm}^{-1}$ are readily assignable to $\mathrm{P}=\mathrm{O}$ and $\mathrm{CO}-\mathrm{H}$ vibrations, respectively. In solution, compound 1 shows a single resonance in the ${ }^{31} \mathrm{P}$ NMR spectroscopy at $\delta 22.6 \mathrm{ppm}$. The observed ${ }^{1} \mathrm{H}$ NMR spectral pattern and the ratio of integrated intensities further lend evidence to the structure of $\mathbf{1}$. The multiplets appearing in the range $\delta 7 \cdot 13-7.22 \mathrm{ppm}$ correspond to the aryl protons. As expected, the methine protons $(\mathrm{C}-\mathrm{H}$ of the isopropyl group) appear as a septet centered at $\delta 4.45 \mathrm{ppm}\left({ }^{3} J_{\mathrm{HH}}=6.6 \mathrm{~Hz}\right)$. The methyl protons $\left(\mathrm{CH}_{3}\right.$ of the isopropyl group) are observed as a doublet at $\delta 1.30 \mathrm{ppm}$. Two singlets of similar intensity appearing at $\delta 1.95$ and $2.00 \mathrm{ppm}$ are assigned to the two methyl groups of the $\mathrm{CMe}_{2}$ moiety attached to phosphorus.

Unlike 1, compound $\mathbf{2}$ does not show any absorption at around $2300 \mathrm{~cm}^{-1}$ in the infrared spectrum indicating the absence of $\mathrm{P}-\mathrm{OH}$ group in the molecule. The ${ }^{1} \mathrm{H}$ NMR spectrum is consistent with the presence of two aryloxides and one $\mathrm{CMe}_{2} \mathrm{OH}$ group on the central phosphorus atom. The ${ }^{31} \mathrm{P}$ NMR spectrum shows a single resonance at $\delta 15.4 \mathrm{ppm}$, which is slightly downfield shifted compared to 1 due to presence of an additional aryloxide on phosphorus.

\subsection{Mechanism}

Since the Mannich type reactions on P-H centers occur only in acidic medium, it is easy to explain the formation of $\mathbf{1}$ and $\mathbf{2}$ in the present case by invoking the mechanism shown in scheme 1. Although the original intention was to convert the phosphorus halides to the corresponding acids $(\mathrm{ArO}) \mathrm{P}(\mathrm{OH})_{2}$ and $(\mathrm{ArO})_{2} \mathrm{P}(\mathrm{OH})$ by hydrolysis, the use of water/ acetone as the reaction medium led to interesting results. Thus, the acids $\mathbf{B}$ or $\mathbf{E}$ formed during the hydrolysis (scheme 1) undergo facile tautomerization to produce the phosphonic acid esters $\mathbf{C}$ or $\mathbf{F}$ with reactive $\mathrm{P}-\mathrm{H}$ bonds (the nucleophile), which are now ready to attack the electrophilic carbonyl group of the acetone used in the reaction medium. Thus the insertion of $\mathrm{P}-\mathrm{H}$ bond in $\mathbf{C}$ or $\mathbf{F}$ into the $\mathrm{C}=\mathrm{O}$ bond leads to the isolation of stable phosphonate mono and diesters 1 and 2 respectively. The $\mathrm{HCl}$ liberated during the hydrolysis of $\mathrm{P}-\mathrm{Cl}$ bond, which has not left the system by dissolution in the residual water, catalyses the last step shown in scheme 1. The yield of the reactions in the present case is probably proportional to the amount of $\mathrm{HCl}$ available in the system during the final step.

\subsection{Molecular structure of 1}

A single crystal X-ray diffraction measurement of 1 indicates that the compound crystallises in mono-
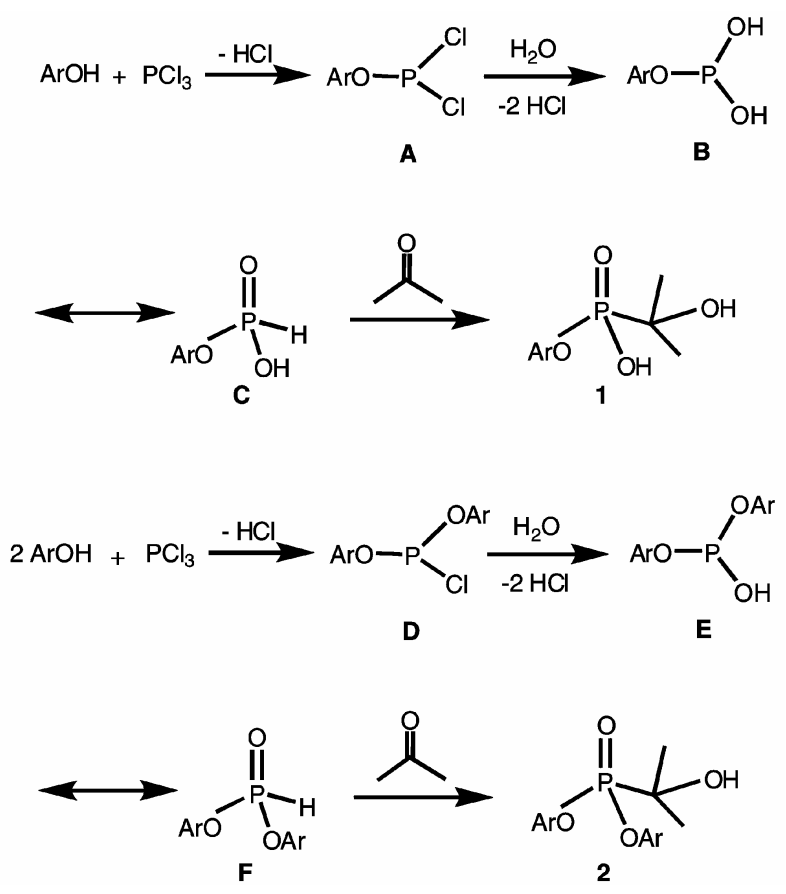

Scheme 1. Plausible pathway for the formation of $\mathbf{1}$ and 2. 
clinic crystal system. The final refined molecular structure is shown in figure 1 along with selected structural parameters. The central phosphorus atom in 1 is surrounded by four different ligands thus rendering the molecule chiral (at least in the solid state, space group $\mathrm{P} 2_{1}$ ) because of the presence of distinct $\mathrm{P}=\mathrm{O}$ and $\mathrm{P}-\mathrm{O}(\mathrm{H})$ moieties $(\mathrm{P} 1-\mathrm{O} 3 \mathrm{1} \cdot 468(2)$ and $\mathrm{P} 1-$ $\mathrm{O} 21.554(2) \AA)$. The $\mathrm{P}-\mathrm{O}(\mathrm{Ar})$ is the longest $\mathrm{P}-\mathrm{O}$ bond in the molecule $(1.580 \AA)$. Due to the presence of bulky $\mathrm{CMe}_{2} \mathrm{OH}$ and $\mathrm{OAr}$ substituents, the tetrahedral angles around phosphorus varies in the range $100 \cdot 5(1)-115 \cdot 3(1)^{\circ}$.

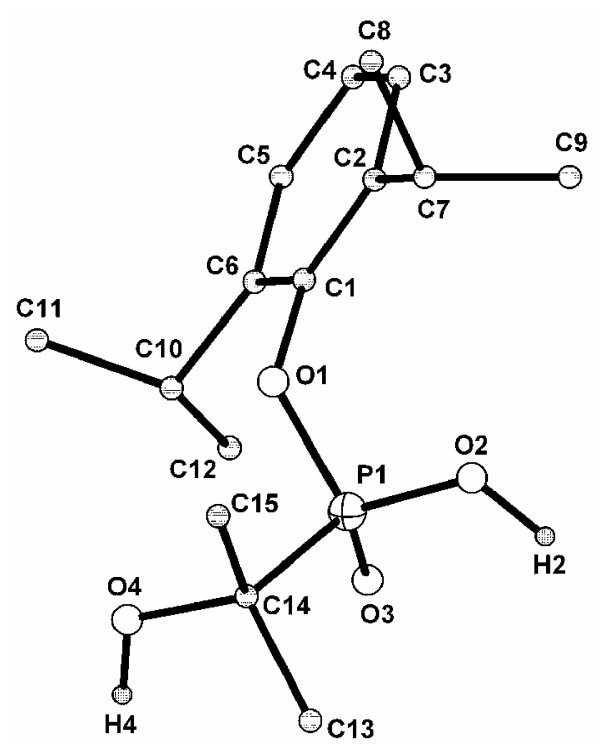

Figure 1. Molecular structure of 1. Selected bond distances $[\AA]: \quad \mathrm{P}(1)-\mathrm{O}(1) \quad 1 \cdot 580(2), \quad \mathrm{P}(1)-\mathrm{O}(2) \quad 1.554(2)$, $\mathrm{P}(1)-\mathrm{O}(3) \quad 1.468(2), \quad \mathrm{P}(1)-\mathrm{C}(14) \quad 1 \cdot 825(3), \quad \mathrm{C}(1)-\mathrm{O}(1)$ $1.424(3), \mathrm{C}(14)-\mathrm{O}(4) 1.443(3)$; bond angles [ $\left.{ }^{\circ}\right]$ : $\mathrm{O}(1)-$ $\mathrm{P}(1)-\mathrm{O}(2) \quad 105 \cdot 1(1), \quad \mathrm{O}(1)-\mathrm{P}(1)-\mathrm{O}(3), \quad 115 \cdot 3(1), \quad \mathrm{O}(1)-$ $\mathrm{P}(1)-\mathrm{C}(14) \quad 100 \cdot 5(1), \mathrm{O}(3)-\mathrm{P}(1)-\mathrm{O}(2) \quad 114 \cdot 3(1), \mathrm{O}(2)-$ $\mathrm{P}(1)-\mathrm{C}(14) 106 \cdot 6(1), \mathrm{O}(3)-\mathrm{P}(1)-\mathrm{C}(14) 113 \cdot 7(1)$.

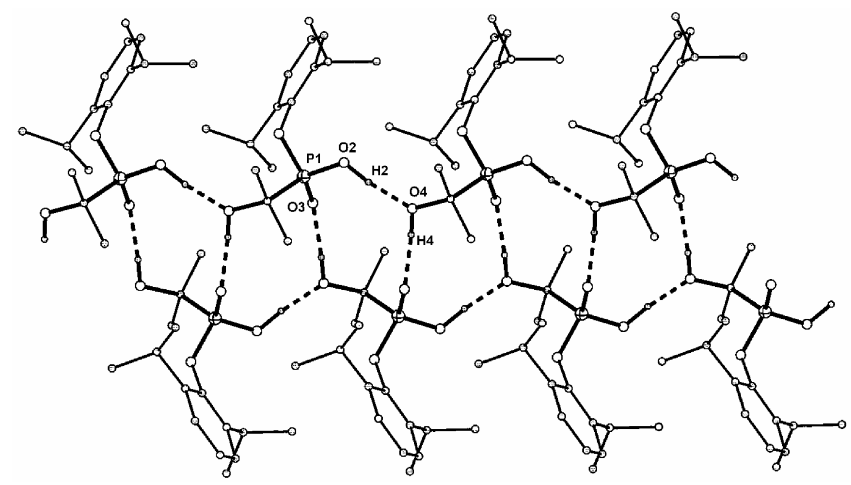

Figure 2. Corrugated sheet-type supramolecular assembly in $\mathbf{1}$.
In solid state, due to the presence of $\mathrm{P}-\mathrm{O}(\mathrm{H}), \mathrm{C}-$ $\mathrm{O}(\mathrm{H})$, and $\mathrm{P}=\mathrm{O}$ moieties, an intricate supramolecular hydrogen bond network is built. Two unique hydrogen bonds found in the lattice $(\mathrm{O} 2-\mathrm{H} 2 \ldots \mathrm{O} 4$ and $\mathrm{O} 4-\mathrm{H} 4 \ldots \mathrm{O} 3$ ) results in the formation of an extended corrugated sheet type of structure as shown in figure 2. (Hydrogen bond parameters: $\mathrm{O} 2 \cdots \mathrm{O} 4=2.589(3) \AA$, $\mathrm{H} 2 \cdots \mathrm{O} 4=1.63(4) \AA, \mathrm{O} 2-\mathrm{H} 2=0.99(4) \AA, \mathrm{O} 2-\mathrm{H} 2 \cdots$ $\mathrm{O} 4=163(4)^{\circ} ; \quad \mathrm{O} 3 \cdots \mathrm{O} 4=2.636(3) \AA, \quad \mathrm{H} 4 \cdots \mathrm{O} 3=$ $\left.1.76(4) \AA, 04-\mathrm{H} 4=0.88(4) \AA, 04-\mathrm{H} 4 \cdots \mathrm{O} 3=169(4)^{\circ}\right)$. The corrugated sheet-type supramolecular assembly with alternating ten membered [HOCPOHOCPO] rings found in $\mathbf{1}$ is rare among structurally characterized phosphonic acid derivatives. ${ }^{21-26}$ For comparison, hydrogen bond assembly of 2,6-diisopropyl phenyl phosphate monoester reveals a polymeric chain, ${ }^{27}$ whereas phosphate diesters ${ }^{28}$ or cyclic phosphates $^{29}$ force a hydrogen bonded dimeric structure with a eight membered ring.

\subsection{Molecular structure of 2}

A single crystal X-ray diffraction measurement of $\mathbf{2}$ indicates that the compound, unlike 1 , crystallizes in the centrosymmetric space group $\mathrm{P} \overline{\mathrm{I}}$ and adopts a dimer motif in the lattice about the inversion centre (figure 3). The appearance of the dimer is highly reminiscent of the characteristic pattern seen for carboxylic and organophosphorus acids, with the $\mathrm{C}$ -

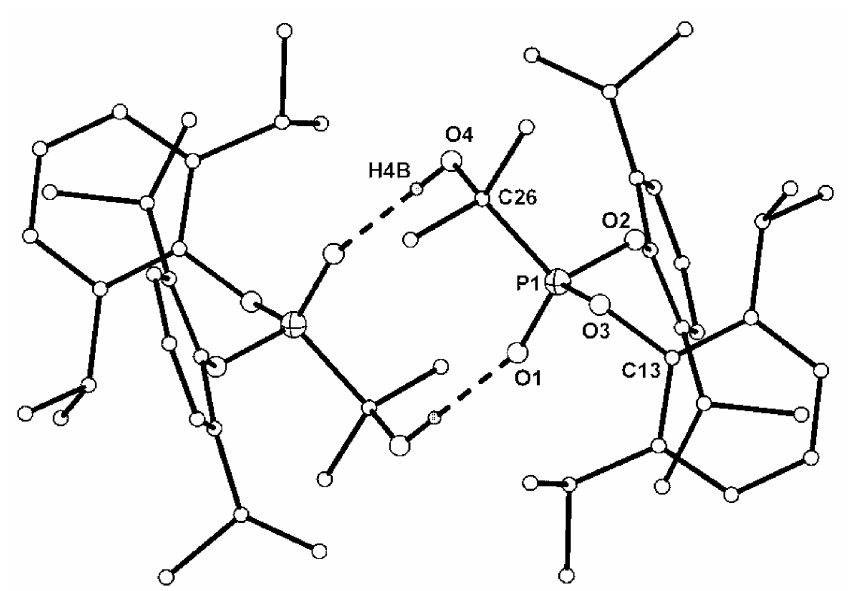

Figure 3. Ten-membered macrocycle formation via O$\mathrm{H}$... O intermolecular hydrogen bonding interaction in 2 . Selected bond distances $[\AA]$ : $\mathrm{P}(1)-\mathrm{O}(1)$ 1.460(2), P(1)$\mathrm{O}(2) 1.594(2), \mathrm{P}(1)-\mathrm{O}(3) 1.594(2), \mathrm{P}(1)-\mathrm{C}(26) 1 \cdot 826(4)$, $\mathrm{C}(1)-\mathrm{O}(2) 1.427(4), \mathrm{C}(26)-\mathrm{O}(4) 1.427(4)$; bond angles [ $]$ ]: $\mathrm{O}(1)-\mathrm{P}(1)-\mathrm{O}(3)$ 116.1(1), O(1)-P(1)-O(2) 112.9(1), $\mathrm{O}(1)-\mathrm{P}(1)-\mathrm{C}(26) \quad 113 \cdot 7(2), \quad \mathrm{O}(3)-\mathrm{P}(1)-\mathrm{O}(2) \quad 102 \cdot 9(1)$, $\mathrm{O}(2)-\mathrm{P}(1)-\mathrm{C}(26) 109 \cdot 9(2), \mathrm{O}(3)-\mathrm{P}(1)-\mathrm{C}(26) 100 \cdot 1(1)$. 


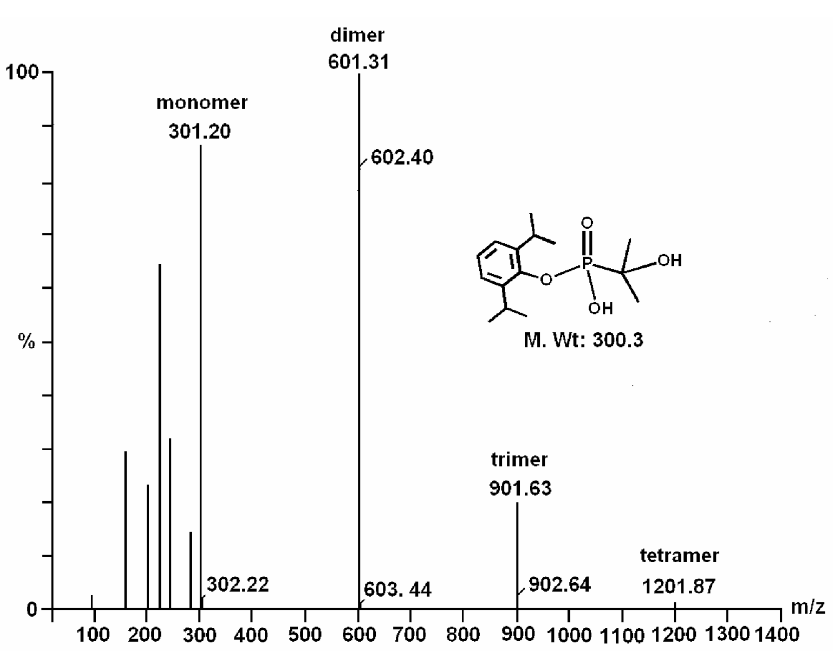

Figure 4. ESI-Mass spectrum of 1.

$\mathrm{OH}$ group of each molecule in $\mathbf{2}$ pointing towards to the $\mathrm{P}=\mathrm{O}$ group of the other crystallographically equivalent molecule, with the exception that the $\mathrm{OH}$ group is not situated directly on phosphorus but on the neighbouring carbon (Hydrogen bond parameters: $\quad$ O4-H4B $=0.76(4) \AA, \quad \mathrm{H} 4 \mathrm{~B} \cdots \mathrm{O} 1=1.97(4) \AA$, $\left.\mathrm{O} 4 \cdots \mathrm{O} 1=2.712(4) \AA \mathrm{O} 4-\mathrm{H} 4 \mathrm{~B} \cdots \mathrm{O} 1=169(4)^{\circ}\right){ }^{30}$ The central phosphorus adopts a distorted tetrahedral geometry $\left(100 \cdot 1(1)-116 \cdot 1(1)^{\circ}\right)$ as in 1 with the average phosphorus angle being $109 \cdot 3^{\circ}$. There are two types of $\mathrm{P}-\mathrm{O}$ bond distances $(\mathrm{P}-\mathrm{O}(\mathrm{C})$ and $\mathrm{P}=\mathrm{O})$, with the former being appreciably longer (1.594(2) $\AA$ ) than the latter (1.460(2) $\AA$ ).

\subsection{Aggregation in solution}

The aggregation of main group compounds containing multiple hydroxyl groups has been of great interest for some time..$^{22}$ The case of silanols associating in solution and in the solid-state has been investigated in detail. ${ }^{31}$ In view of the strikingly different solid state aggregation (H-bonding pattern) of 1 and 2, ESI-mass spectral studies were carried out in solution in order to see any such association behaviour is prevalent also in solution. As it has been shown in figure 4, the molecular ion for 1 appears at $\mathrm{m} / \mathrm{z} 301$. In addition to this additional peak at $\mathrm{m} / \mathrm{z} 601$ and 901 are also observed with appreciable intensity, which correspond to the dimeric and trimeric forms of 1 (in fact the base peak corresponds to the dimer). The weak peak observed at $\mathrm{m} / \mathrm{z} 1201$ corresponds to the tetrameric form of 1 , suggesting that inspite of presence of two bulky substituents on phosphorus, compound 1 does undergo facile aggregation in solution. The picture however changes drastically for 2, where the molecular ion is observed at $\mathrm{m} / \mathrm{z} 461$ and no other signals corresponding to the formation of any aggregates with higher mass number. This is however explainable because of the introduction of an additional aryloxide on phosphorus as well as the removal of acidic $\mathrm{P}-\mathrm{O}(\mathrm{H})$ proton, compared to $\mathbf{1}$.

\section{Conclusion}

In conclusion, we have demonstrated in this preliminary communication a facile, one-pot synthesis for the preparation of functional phosphonate esters by a simple acetone insertion reaction under mild acidic conditions. Hydrolysis of $\mathrm{P}-\mathrm{Cl}$ bond in the presence of electron deficient acetone carbonyl centre leads to the in situ formation of the products. This methodology could open up new possibilities in making newer phosphonates. Further, compounds 1 and 2 could be used as ligands in rapidly expanding main group and transition metal phosph(on)ate chemistry. We are currently exploring these possibilities.

\section{Acknowledgements}

This work was supported by the Department of Science and Technology (DST) in the form of a Swarnajayanti Fellowship. We thank the DST funded National Single Crystal Diffraction Facility at Indian Institute of Technology (IIT) Bombay for the diffraction data and SAIF, IIT Bombay for the spectral data.

\section{References}

1. Muthiah C, Praveen Kumar K, Aruna Mani C and Kumara Swamy K C 2000 J. Org. Chem. 653733 and references therin

2. Kumara Swamy K C and Sathis Kumar N 2006 Acc. Chem. Res. 39324

3. Walawalkar M G, Roesky $\mathrm{H}$ W and Murugavel R 1999 Acc. Chem. Res. 32117

4. Murugavel R and Shanmugan S 2007 Chem. Commun. 1257

5. Murugavel R, Walawalkar M G, Dan M, Roesky H W and Rao C N R 2004 Acc. Chem. Res. 37763

6. Murugavel R, Kuppuswamy S, Boomishankar R and Steiner A 2006 Angew. Chem. Int. Ed. 455536

7. Murugavel R and Kuppuswamy S 2006 Angew. Chem. Int. Ed. $\mathbf{4 5} 7022$ 
8. Pothiraja R, Sathiyendiran M, Butcher R J and Murugavel R 2005 Inorg. Chem. 446314

9. Murugavel R, Sathiyendiran M, Pothiraja R and Butcher R J 2003 Chem. Commun. 2546

10. Murugavel R, Sathiyendiran M and Walawalkar M G 2001 Inorg. Chem. 40427

11. Horak J and Ettel V 1961 Collection of Czechoslovak Chem. Commun. 262401

12. Redmore D 1976 Top. Phosphorus Chem. 8515

13. Moedritzer K and Irani R R 1966 J. Org. Chem. 311603

14. Redmore D $1978 \mathrm{~J}$. Org. Chem. 43996

15. Redmore D 1978 J. Org. Chem. 43992

16. Drag M, Grzywa R and Oleksyszyn J 2007 Bioorg. Med. Chem. Lett. 171516

17. Plazuk D, Zakrzewski J and Rybarczyk-Pirek A 2006 J. Organomet. Chem. 6913098

18. Farrugia L J WinGX Version $1.64 .051999 \mathrm{~J}$. Appl. Crystallogr. 32837

19. Altomare A, Cascarano G, Giacovazzo C and Gualardi A 1993 J. Appl. Crystallogr. 26343

20. Sheldrick G M SHELXL-97 Program for structure refinement 1997 University of Göttingen: Germany
21. Chandrasekhar V, Sasikumar P, Boomishankar R and Anantharaman G 2006 Inorg. Chem. 453344

22. Mehring M, Schurmann M and Ludwig R 2003 Chem. Eur. J. 9837

23. Weakley T J R 1976 Acta Crystallogr. B32 2889

24. Aragoni M C, Arca M, Blake A J, Lippolis V, Schröder M and Wilson C 2002 Acta Crystallogr. C58 260

25. Merz K and Knüfer A 2002 Acta Crystallogr. C58 187

26. Yi X Y, Li Y Z and Zheng L M 2002 Acta Crystallogr. E58 820

27. Onada A, Okamura T, Yamamoto $\mathrm{H}$ and Ueyama $\mathrm{N}$ 2001 Acta Crystallogr. E57 1022

28. Murugavel R unpublished results (structure of di-tert butylphosphate)

29. Kumara Swamy K C, Kumaraswamy S and Kommana P $2001 \mathrm{~J}$. Am. Chem. Soc. 12312642

30. Etter M C 1984 Acc. Chem. Res. 23120

31. Chandrasekhar V, Boomishankar R and Nagendran S 2004 Chem. Rev. 1045847 